\title{
Occurrence, Composition and Formation of Ruppia, Widgeon Grass, balls in Saskatchewan Lakes
}

\author{
Randy W. Olson ${ }^{1}$, Josef K. Schmutz ${ }^{2,3}$, and U. TheOdore Hammer ${ }^{4}$ \\ ${ }^{1}$ W. P. Fraser Herbarium, University of Saskatchewan, 51 Campus Drive, Saskatoon, Saskatchewan S7N 5A8 Canada \\ ${ }^{2}$ Centre for Studies in Agriculture, Law and Environment, University of Saskatchewan, 51 Campus Drive, Saskatoon, \\ Saskatchewan S7N 5A8 Canada \\ ${ }^{3}$ Corresponding author Schmutz. joe.schmutz@usask.ca \\ ${ }^{4}$ Department of Biology, University of Saskatchewan, 112 Science Place, Saskatoon, Saskatchewan S7N 5E2 Canada
}

Olson, Randy W., Josef K. Schmutz, and U. Theodore Hammer. 2005. Occurrence, composition and formation of Ruppia, Widgeon Grass, balls in Saskatchewan Lakes. Canadian Field-Naturalist 119(1): 114-117.

Widgeon Grass (Ruppia maritima) is an aquatic vascular plant (Ruppiaceae) which has been the source for rare balls of plant material found at the shores of lakes on four continents. In North America, the lakes involved were in North Dakota, Oregon, and now northern and southern Saskatchewan. The formation of the balls has not been observed in nature, but similar balls have been produced in other studies with Posidonia or Turtle Grass (Hydrocharitaceae) fibers under the wavelike action in a washing machine. Our samples are from a saline lake in southern Saskatchewan $\left(49^{\circ} \mathrm{N}\right)$, and an over 40 -year-old sample from an unknown lake north of the boreal transition zone $\left(52^{\circ} \mathrm{N}\right)$. Comparisons of the plant material with herbarium specimens confirm that the balls are almost entirely comprised of Ruppia maritima, with minor items including invertebrate animal parts, sand pebbles and feathers. The context in which the material was found is consistent with the proposition that they are formed by Ruppia inflorescences breaking apart, drifting to near shore due to wind and being rolled into balls by wave action.

Key Words: Ruppia maritima, Widgeon Grass, plant balls, saline lake, Saskatchewan.

Unusual balls of plant material were encountered at shores of two different lakes in northern and southern Saskatchewan. Judging from available literature, similar balls have been found in Europe, North America and New Zealand (Cannon 1979; Essig 1948; Gerbeaux and Ward 1986). While the actual formation of these balls has not been observed in nature, the combined action of waves on fragments of aquatic vegetation near shores is thought to be involved. Such balls have, however, been produced using Posidonia or Turtle Grass (Hydrocharitaceae) fibers under the wave-like actions simulated by a washing machine (Cannon 1979).

Names for the plant balls exist in Dutch, English, French, German and Italian, 15 names in total (McAtee 1925). Some of these names date back to classical times (E. A. Parry in Cannon 1979). This attests to a widespread, even if rare, occurrence of these balls. The names also attest to a degree of fascination; a curiosity likely enhanced by the unpredictable occurrence of these structures in nature.

\section{Sample Sources}

Our collection includes six balls of plant material in two sets. One set was located at Sandoff Lake $\left(49^{\circ} 00^{\prime} \mathrm{N}\right.$, $104^{\circ} 18^{\prime} \mathrm{W}$ ) in the Lake Alma Upland within the Missouri Coteau of south-central Saskatchewan. Sandoff Lake is a $1 \mathrm{~km}^{2}$ saline lake in a hill-and-dale landscape. Sandoff Lake has no above-ground outflow, and lies in the Missouri-Mississippi River drainage (Fung et al. 1999). As is typical of many saline lakes, it is probably fed through ground water in addition to runoff and springs visible on the lake's shore. Sandoff Lake goes dry in some or most years. On 20 October 2000 there was no standing water covering the white salt flat.

A second set of plant balls was found during lake studies in the 1950s by D. S. Rawson (e.g., Rawson and Moore 1944). The balls were given to UTH about 1960, but data on time and location of collection were not recorded. The collection has been given to Glenn Sutter, for inclusion in the natural history collections of the Royal Saskatchewan Museum in Regina (RSM Accession 17443).

\section{Results and Discussion}

More than 50 plant balls were first found on 6 July 2001 by JKS along the southeastern shore of Sandoff Lake (Figure 1) where the prevailing winds are northwesterly. The balls were scattered in a band approximately $3 \mathrm{~m}$ wide and $100 \mathrm{~m}$ long, at the high water mark where the pebbly shore merges with shortgrass prairie. The balls were still present, although more encrusted in salt, on 30 June 2003. Their position in a single layer, similarity in salt or algal coverage and slightly compressed form suggests that only one generation of such balls occurred during the three years. Their position at the upper reaches of the shore suggests that the balls may have been washed there during strong winds but not returned to the lake with the receding water during calmer weather. A walk around the lake revealed two sets of balls on the east but none on the west (primarily upwind) shore.

Analysis of the material in the two sets of balls showed that they were composed mainly (greater than 95\%) of Ruppia inflorescence stems, peduncles, and 
fruits. The fruits were black, ca. $2 \mathrm{~mm}$ long, and beaked. These identifications were based on comparisons between the samples and specimens from the W. P. Fraser Herbarium, and descriptions from several floras (e.g., Haynes 2000). In three of the balls from Sandoff Lake, Ruppia maritima L. was identifiable. Small amounts of other material found included twigs, small pebbles, and a feather.

Saskatchewan has two species of Ruppia: $R$. cirrhosa (Petagna) Grande (synonym $=R$. occidentalis $\mathrm{S}$. Wat.) and R. maritima L. (Harms 2003). Ruppia maritima is found in the southern third of Saskatchewan, and Ruppia cirrhosa is found in the southern half of the province (Hammer and Heseltine 1988; W. P. Fraser Herbarium). In North America, Ruppia maritima is found throughout eastern and western coastal regions (Haynes 2000). Ruppia cirrhosa is found from Alaska south to Texas and From California east to the Great Lakes (Haynes 2000).

The two species of Ruppia belong to Ruppiaceae, the Ditch-grass family, also known as Widgeon Grass (Haynes 2000), The one genus includes approximately 10 species worldwide, and two in North America. Ruppia is an annual, or rarely perennial, sessile herb submersed in brackish or saline water. Flowering occurs spring-fall.

The plant balls as shown by Essig (1948), and Swanson and Springer (1972) are highly similar to our material. Also, $R$. maritima $\mathrm{L}$. seems to be the primary plant species involved, at least in North America (Table 1). This suggests that the conditions that favour ball formation are relatively specific. The involvement of saline

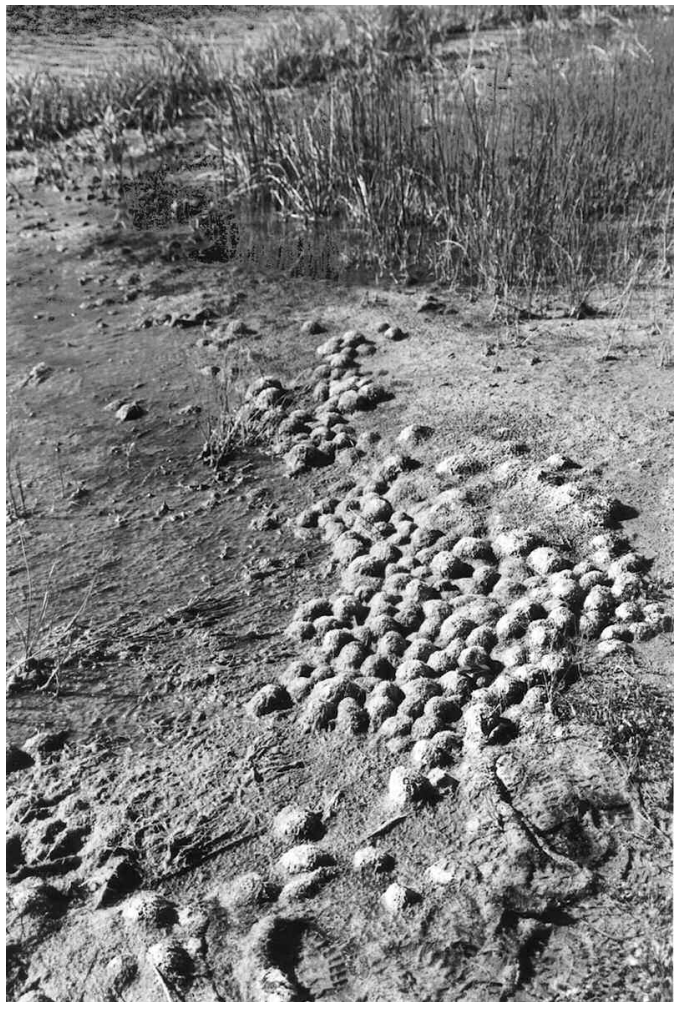

FIGURE 1. Ruppia maritima balls located at the southwest shore of Sandoff Lake in Saskatchewan, on 6 July 2001 .

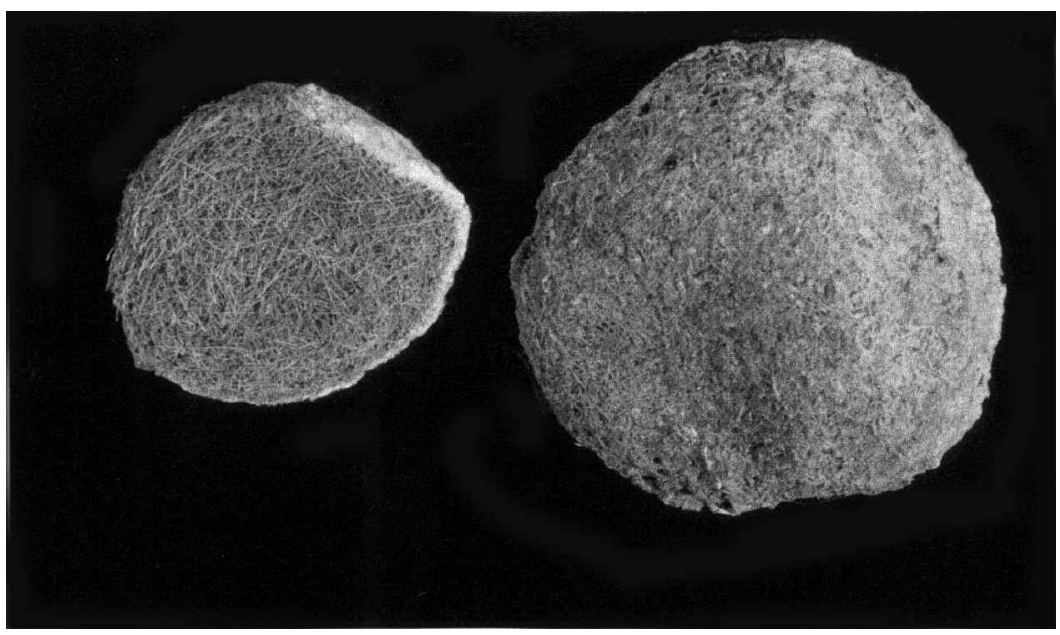

Figure 2. Two Ruppia maritima balls. One (left, $6.0 \mathrm{~cm}$ diametre) from Sandoff Lake, and the larger (right, $13.5 \mathrm{~cm}$ ) from northern Saskatchewan. 
TABLE 1. Characteristics of plant balls as reported in the literature and found in our Saskatchewan samples.

\begin{tabular}{|c|c|c|c|c|}
\hline Site Name & Location & Lake Type & Plant Species & Reference \\
\hline No name & NE North Dakota & Saline & Ruppia maritima & SS 1972 \\
\hline Mediteranean & - & Sea shore & Posidonia oceanica & JFMC 1979 \\
\hline No name & Near Dawson, ND & Saline & Ruppia maritima & FPM \\
\hline Miller Lake & Oregon & - & "similar" to FPM & GWF \\
\hline Little Borax Lake & California & Saline & Ruppia maritima & EOE 1948 \\
\hline Sandoff Lake & S Saskatchewan & Saline & Ruppia maritima & This report \\
\hline Unknown & N Saskatchewan & Unknown & Ruppia maritima & This report \\
\hline
\end{tabular}

References: SS = Swanson and Springer 1972, JFMC = Cannon 1979, FPM = F.P. Metcalf in McAtee 1925, GWF = G. W. Field in McAtee 1925, EOE = E.O. Essig 1948.

lakes may not be crucial to ball formation but merely reflect that Ruppia is a saltwater species. The stems of Ruppia are delicate, relying on the surrounding water to support their mass (Kantrud 1991*). The stems are likely susceptible to breakage during periods of unusual turbulence. The stem bases also decay as the plants reach senescence (Kantrud 1991*). These two factors would leave large amounts of plant material in the water in late summer and/or fall, likely leading to the homogeneous content of the Ruppia balls.

Given the structure of the balls, the location in which they were found and explanations from the literature, we suggest that the following mechanisms are involved in their formation. The fibrous stalks of Ruppia are prone to breakage and to sticking together. Two balls that were cut (Figure 2) and one that was teased apart suggest that the material is Ruppia throughout and does not contain any other material in its core. When the stems of the Ruppia break and tangle together, floating mats accumulate and are driven by wind to the shore (e.g., Essig 1948). Here, the repeated wave action in combination with the resistance provided by the shore in shallow water rolls the mat back and forth. This rolling action was thought responsible for producing balls of plant material in the lint trap of a washing machine (Cannon 1979). Finally, on windy days the balls may be washed up onto shore out of reach of the lapping waves on calm days that might otherwise return the balls to water where they may decay. The distribution of balls at Borax Lake (Essig 1948) suggests that the balls were deposited over time as water evaporated and the shallow lake receded, differing slightly from our accumulation at the shore. Judging from the misaligned fibers in our material, interconnected in seemingly all directions (Figure 2), we doubt that the balls have grown in layers (e.g., Essig 1948). Instead, the different sized balls may simply be due to different amounts of plant material in a mat that starts to roll on the shore. In the Sandoff Lake sample, salt spray had encrusted the balls and, combined with grass shoots growing through the balls, had firmly anchored the balls on the upper shore. The Sandoff Lake balls tended to be oval. We suggest that they were round originally but that the material settled to an oval shape after they were covered in salt, dried and became anchored on the shore.
The formation of balls by wave/wind action and friction is not limited to aquatic plants. Near Blaine Lake, Saskatchewan, wind combined with large and wet snowflakes led to snowball formation observed on the packed snow in a yard (Julie Hupé, personal communication). Pierce et al. (2004) compared amorphous, decomposed remains of large animals that washed up on a Chilean shore in 2003 (Chilean Blob), with other such "carcasses" variously reported as sea monsters for over a century. Such sightings occurred in Bermuda $(n=2)$, West Coast of Tasmania, and Northeast Coast of the United States in addition to Chile. The authors identified the material as decomposed remains of large whales. The material was held together by cross-hatched layers of collagen fibers. This flexible layering of collagen in a blob was different from the firm arrangement of the inflorescence stems in our Ruppia balls.

\section{Acknowledgments}

Dennis Dyck kindly took the photo of the balls and Blaine Novakowski sliced them for analysis. Glenn Sutter cataloged the material as part of the Royal Saskatchewan Museum's collections (RSM Accession 17443).

Documents Cited (marked * in text)

Kantrud, H. A. 1991. Wigeongrass (Ruppia maritima L.): A literature review. U.S. Fish and Wildlife Service, Fish and Wildlife Research 10. Jamestown, North Dakota: Northern Prairie Wildlife Research Center Home Page. http://www.npwrc.usgs.gov/resource/literatr/ruppia/rup pia.htm (Version 16JUL97).

\section{Literature Cited}

Cannon, J. F. M. 1979. An experimental investigation of Posidonia balls. Aquatic Botany 6: 407-410.

Essig, E. O. 1948. The Ruppia balls of Little Borax Lake. Science Monthly 66: 467-471

Fung, K., B. Barry, and M. Wilson. Editors. 1999. Atlas of Saskatchewan. University of Saskatchewan, Saskatoon, Saskatchewan.

Gerbeaux, P., and J. Ward. 1986. The disappearance of macrophytes and its importance in the management of shallow lakes in New Zealand. Pages 119-124 in Proceedings of the $7^{\text {th }}$ International Symposium on Aquatic Weeds, European Weed Research Society and Association of 
Applied Biologists. Loughborough University of Technology, Loughborough, Leicestershire, England, 15-19 September.

Hammer, U. T., and J. M. Heseltine. 1988. Aquatic macrophytes in saline lakes of the Canadian prairies. Hydrobiologie 158: 101-116.

Harms, V. L. 2003. Checklist of the vascular plants of Saskatchewan, and the provincially and nationally rare native plants in Saskatchewan: Including important synonyms, authorities, common names, and various status indicators. University of Saskatchewan Extension Press, Saskatoon, Saskatchewan.

Haynes, R. R. 2000. Ruppiaceae Hutchinson, Ditch-grass Family. Pages 75-76 in Flora of North America. Edited by the Flora of North America Editorial Committee, Volume 22, Oxford University Press, New York.
McAtee, W. L. 1925. Notes on drift, vegetable balls, and aquatic insects as a food product of inland waters. Ecology 6: 288-302.

Pierce, S. K., S. E. Massey, N. E. Curtis, G. N. Smith, Jr., C. Olavarría, and T. K. Maugel. 2004. Microscopic, biochemical and molecular analysis of the Chilean Blob and a comparison with the remains of other sea monsters: Nothing but whales. Biological Bulletin 206:125-133.

Rawson, D. S., and J. E. Moore. 1944. The saline lakes of Saskatchewan. Canadian Journal of Research 22: 141-201. Swanson, G. A., and P. F. Springer. 1972. Widgeongrass balls on alkali lakes. The Prairie Naturalist 4(2): 52-54.

Received 23 April 2004

Accepted 11 February 2005 